\title{
Home Bias in Online Employment
}

\author{
Chen Liang \\ Arizona State University \\ chen.liang.4@,asu.edu
}

\author{
Yili (Kevin) Hong \\ Arizona State University \\ hong@asu.edu
}

\author{
Bin $\mathrm{Gu}$ \\ Arizona State University \\ bin.gu@asu.edu
}

\begin{abstract}
We study the nature of home bias in online employment, wherein the employer prefers workers from his/her own home country. Using a unique largescale dataset from one of the major online labor platforms, we identify employers' home bias in their online employment decisions. Moreover, we investigate the cause of employers' home bias using a quasi-natural experiment wherein the platform introduces a monitoring system to facilitate employers to keep track of workers' progress in time-based projects. After matching comparable fixed-price projects as a control group using propensity score matching, our differencein-difference estimations show that the home bias does exist in online employment, and at least $54.0 \%$ of home bias is driven by statistical discrimination.
\end{abstract}

\section{Introduction}

Firms usually make employment decisions under high uncertainty due to information asymmetry [1]. Such decision uncertainty leads employers to employ heuristics to help infer workers' capability and diligence $[2,3]$. Two heuristics commonly examined in the literature are discrimination based on the racial group membership and that based on gender. For example, employers were found to prefer white workers to black workers (the minority group), even though they have the same observable characteristics [4]. While the singledirectional discrimination against minority groups is well-known, little prior research has considered another form of discrimination - the minority group could have a preference for applicants from the same minority group. A notable example demonstrating the importance of the matching between managers and workers is that managers at Oracle, most of whom are Asians, were involved in a lawsuit because of their discrimination against qualified white workers and in favor of Asians who were belonged to the minority group in the previous discrimination literature. ${ }^{1}$ This anecdote underscores that sometimes it is the similarity or closeness between two parties playing a critical role in determining the discrimination pattern and the employment choice.

The literature has documented such discrimination as "home bias," which is a preference for parties with shorter geographic distance [5]. Home bias has been extensively documented, in areas such as portfolio management [6], P2P lending [7], various products from the same city [5]. The existence of home bias is plausible yet potentially detrimental in employment settings. For one thing, home bias tends to lower the diversity of the employees [8], which in turn lowers the creativity [9]. For another, home bias also adds friction to the labor markets and serves as one type of unconscious biases that makes the employment decisions unfair to some workers [4]. Important as the question is, there is little academic evidence documenting home bias in employment. And the lack of evidence is not surprising, given the geographic homogeneity of workers in the offline employment relationship. In this paper, we seek to fill this gap and investigate the discrimination based on the similarity of home country by using a unique data set from the online employment setting, wherein we are able to reliably observe both the employer and workers' countries.

The literature has offered explanations for the home bias, in particular, for investment portfolios and international trade [10]. Generally, these explanations could be classified as two forms of bias, namely, statistical/rational discrimination $[11,12]$ and tastebased discrimination [7, 13]. Specifically, statistical discrimination refers to decision makers' higher preference for domestic portfolios or trade because of the associated higher expected utility inferred based on individual-specific and group-specific signals [14, 15]. In contrast, taste-based discrimination comes from the pre-existing liking for domestic portfolios or trade, which is not related to the signal exaction or utility function [16]. Based on the extant literature, the home bias in investment portfolios might be driven by statistical or taste-based discrimination. Specifically, it could come from established institutional factors [17], investors' rational desire to hedge specific sources of

\footnotetext{
${ }^{1}$ http://fortune.com/2017/01/18/labor-department-oracle/
} 
risk [11], or simply their reluctance to share risks with foreigners [13]. However, in the employment setting, these concerns about risk hedging or risk sharing do not appear applicable. Additionally, studies in international trade suggest that international trade barriers $[12,18]$, localized consumption of the goods and the possibility of direct contract enforcement [5] are the major rational explanations for a home bias. However, because typically there is little barrier to entry for users from different countries and well-established platform arbitration in online labor markets, these explanations do not appear to apply either. Meanwhile, home bias in employment also differs from the home bias in the financial markets or trade because of its information distribution characteristics. To be specific, unlike the financing or trade decision, the employment decision is plagued with both the salient ex ante and ex post information asymmetry. On the one hand, in such a highly risky context, decision makers tend to elaborate more on the potential economic outcomes and be less likely to solely rely on simple heuristics. On the other hand, more asymmetric information might render the employment decision more effortful and resourceconsuming, and subsequently strengthen managers' reliance on heuristics, especially when the number of worker candidates is high and most of them are similar in some aspects. Therefore, the existence of home bias is more unpredictable and complex in the employment scenario. Bearing the above in mind, we seek to extend the literature in home bias by examining employment decisions in online labor markets $[19,20]$ and specifically, we address the following two research questions:

- $\quad$ Q1 (existence): Is there home bias towards workers based on nationality in online labor markets?

- Q2 (mechanism): If so, what drives home bias in this market? Is such home bias based on statistical discrimination or taste-based discrimination?

In this study, we identify the existence of and explore the potential mechanism for employment home bias by leveraging a natural experiment -- the initial implementation of a monitoring system in Freelancer.com. This event serves as an exogenous shock to the level of information asymmetry by reducing worker hidden actions. Based on the different theoretical predictions of corresponding mechanisms, we seek to identify the underlying mechanism of discrimination. Specifically, on the one hand, because of the monitoring system lower employers' reliance on group-specific signal extraction by alleviating the ex post individual-specific information, the implementation of the monitoring system should lower the home bias driven by statistical discrimination. On the other hand, taste-based home bias should not be affected by the change in individual information availability and remain constant. Our econometric identification hinges on the fact that the monitoring system is only applicable to time-based contracts (online employment contracts) but not to fixed-price contracts (the sale contracts of outsourcing service), which allows us to use time-based contracts as the treatment group and fixed-price contracts as the control group. Based on a unique large-scale dataset from one of the prevalent online labor markets, we document the existence of home bias towards workers in the employment setting. Further, our result suggests that at least $54.0 \%$ of employers' home bias is statistical-based.

Our paper contributes to the stream of literature in two ways. First, our study is among the first to investigate the existence of home bias in the employment setting and explore the discrimination mechanism with a quasi-natural experiment. It extends previous equity or trade home bias research, which mainly focuses on decisions under ex ante information asymmetry, to the employment decision threatened by both ex ante and ex post information asymmetry. Also, given that the online employment context provides us a rare opportunity to explore the home bias without the mixture of social referrals or organization culture, this paper advances the employment discrimination research by demonstrating the impact of the similarity between the managers and workers. Second, our paper adds to our understanding of potential discrimination in the "Gig" economy. During the last few years, "Gig" economy platforms provide the digital infrastructure that connects demand and on-demand service and brings reorganization of a wide variety of traditional markets. However, even though the "Gig" economy seems to provide a "frictionless" avenue of low entry barrier for the two-sided matching, some emerging research suggests that it also develops into a breeding ground of "racial discrimination" $[21,22]$, which is legally banned in the traditional markets but is out of reach of such antidiscrimination laws [22-24]. Our study showcases the existence of another type of discrimination, home bias, and suggests that platforms' information policies such as monitoring could help to alleviate the statistical home bias.

\section{Theoretical background}

\subsection{Home bias}

Home bias has been reported in multiple contexts, such as financial markets [7, 25-27] and trade [5, 12, 18, 20]. Many papers on home bias focus on offline contexts [10]. For instance, Lewis [13] finds that the reluctance to share the international risk helps to explain the observed "equity-home-bias". Moreover, Coval and Moskowitz [6] suggest that the home bias phenomenon is not only limited to the preference for the equity at the home country, but also can be presented as the 
preference for equity in a shorter geographic distance without crossing the country borders.

As the development of online trade and online financial markets, recent work starts to explore whether the geography-based preference still holds in the online setting. Specifically, most the related studies focus on how the geography-based explanation and culture factors might lead to home bias. On the one hand, some studies suggest that the shorter geographic distance per se is associated with a higher preference because of rational considerations or pre-existing taste. For instance, Hortaçsu et al. [5] find that the city-limits, goods needed to locally consume, the possibility of contract enforcement and cultural factors might jointly contribute to the concentration of local trade on eBay. Lin and Viswanathan [7] explore the home bias in online peer-to-peer markets and find it might be driven by taste-based preference. On the other hand, there is also a stream of literature suggesting that the culture factor plays an important role in the country-level home bias. However, the extant findings of the mechanism of culture-related home country bias are still mixed. For instance, Ghani et al. [20] find that Indians show ethnical discrimination when making the outsourcing decisions. Moreover, Gefen and Carmel [19] find that most employers prefer to purchase the outsourcing service from parties in their home countries. Burtch et al. [28] suggest that there exists a substitutional relationship between cultural differences and physical distance in the online pro-social lending context. Overall, the afore-mentioned explanations and the mechanisms of home bias are still inclusive [7, 13]. Additionally, given that the rich literature on of home bias in the online and offline financial markets and trade, none of the previous literature explore the home bias in the employment setting.

Regarding the methodology of home bias, scholars tend to employ different methods according to their levels of analysis. When the available data is at the macro-level, a typical test would be the gravity equation [29]. Similar to a Cobb-Douglas production function, the gravity equation is a power function of the distance between two parties, the economy volume traded between two parties and other related factors. This method is more applicable to the macro economy research, especially the trading between two countries or cities. When micro-level data is accessible, some alternative methods would be the choice models [20] or the potential-dyads approach used in Lin and Viswanathan [7]. Specifically, when the decision makers' consideration sets are not well-specified, potential dyads analysis enables scholars to include all the available alternatives into the model and explore whether the decision makers have a stronger preference for parties from their home country [25].

\subsection{Mechanisms of Discrimination}

Discrimination is derived from the information asymmetry between workers and employers in online labor markets. Given the limited information regarding workers' capability and effort, employers rely on the observable signal to extrapolate the individual workers' characteristics. There are a lot of mechanisms proposed by researchers to explain the discrimination. Based on the decision rule, discrimination can be classified as rational/statistical discrimination and taste-based discrimination [30]. Specifically, rational or statistical discrimination means employers are profit-maximizing actors, who use the group-specific signal to infer the characteristics of individual workers [15]. For instance, if the employer learns that domestic workers are more skillful and diligent based on his/her private information, he/she might use the country as the signal to infer the workers' quality later, given the limited information and cognitive resource. On the other hand, taste-based discrimination captures employers' pure preference which does not involve any rational inference or the utility function [16, 20,31].

Regarding how to disentangle statistical discrimination from the taste-based counterpart, the most common method employed in the previous discrimination literature is comparing the different gaps between groups under different scenarios [32] and verifying the predictions. Generally, it could be classified into two types of predictions, namely, the static and dynamic predictions [33]. First, the static predictions are about the static difference across between-group pairs when other observable productivity characteristics are unfavorable or favorable [32]. In line with this logic, we could predict that statistical discrimination would be weaker when between-group parties with high observable productivity characteristics are compared, while the magnitude of discrimination would be stronger when between-group parties with low observable productivity characteristics are compared. Second, the dynamic prediction refers to the prediction about when and how the discrimination within the similar pairs of minor and non-minor groups will change [33]. For instance, when people can have chances to correct their beliefs because of the market competition or more information is available, they are expected to change accordingly if they hold statistical discrimination [31]. For instance, Rubineau and Kang [20] state that the medical training should help students to learn to obtain more hard-toobserve characteristics and lower their statistical discrimination. However, they observe that students tend to show a strong discrimination after a year of training, which suggests that it is not statistical discrimination that drives the racial disparities [19]. Based on the dynamic predictions of statistical 
discrimination, information changes such as the removal of gender information [34] or criminal background information [35] will lead to a change in the magnitude of discrimination. On the whole, checking the result if it is consistent with the dynamic prediction is an emerging way to identify statistical discrimination.

\subsection{Online Labor Markets and Contract Types}

Online labor markets facilitate the purchase of ondemand labor services across the borders of cities or countries [36]. Generally, in online labor markets, there are two prevalent ways to buy service from unknown parties, namely, sales contracts (fixed-price contracts) or employment contracts (time-based contracts) [37, 38]. Sales contracts (fixed-price contracts) are outcomedriven, and the agent gets a fixed payment until he/she can provide a given amount of output [39]. On the other hand, employment contracts (time-based contracts), also named as cost-plus contracts, require that the payment should be calculated based on the worker's hourly wage and his/her actual work time in the work process [39]. Because usually workers' compensation is not depending on their performance in time-based projects, moral hazard issues related to ex-post information asymmetries (e.g. their actual effort spent on the projects) tend to pose a big threat to incentive design and employers' benefit. Moral hazard problems are prevalent in the traditional offline employment relationship and online employment relationship wherein the problems might be even more serious because of the spatial and temporal separation between employers and workers.

When information about workers' characteristics is limited and hard to observe, one way to reduce the uncertainty of employment decision is statistical inference $[2,3]$. For instance, by combining the average characteristics of the specific group and the observable individual information, employers can better predict workers' behaviors, which might lead to statistical discrimination [40]. It is also found that sometimes statistical discrimination might help to increase efficiency [41]. Another major way to reduce moral hazard problems by reducing ex post information asymmetries is acquiring more actual performance information, such as monitoring [42]. By tracking and verifying workers' behaviors, monitoring could provide more procedural progress information and alleviate employers' uncertainty about workers' shirking [43].

\section{Hypotheses development 3.1. Employers' Home Bias}

When monitoring systems are not available, employers bear a high moral hazard risk. Specifically, given that the spatial and temporal separation between employers and workers, it is costly for employers to overcome the difference in time zones and collect the information to infer workers' efforts. Moreover, even when employers are willing to spend enough time and effort to manually monitor workers' work flows, it is unlikely that employers could monitor workers' performance precisely. As such, relational contracting or "process-based trust" [44] might serve a more costefficient way to lower the moral hazard risk. Here, trust is defined as one decision maker's specific level of subjective probability with which another party will implement a desirable action before the actual action is monitored or verified [45, 46]. According to Gulati's [46], perceived familiarity could breed the cognitive and emotional base of trust, which helps to alleviate the moral hazard concern and leads to a preference in the employment choice. Given that employers tend to feel more familiar with domestic workers [46], they will be more likely to develop a higher level of initial trust in domestic workers. Therefore, assuming that employers are rational and trying to maximizing their profits from the employment relationship, perceived familiarity and trust might be employed by them to lower the risk and uncertainty. Additionally, the preference for domestic workers might be subliminal. According to the "mere exposure theory" [47], people tend to show a stronger liking for something that is familiar to them without notice. As such, it is possible that employers would prefer domestic workers, even when foreign workers have the comparable productivity. Since the risk is mainly allocated on employers who are faced with both hidden information issues and hidden action (moral hazard) issues [48], employers may more rely on trust or familiarity to lower their uncertainty or risk. Therefore, based on the rational tradeoff or subliminal preference, employers would prefer hiring domestic workers, especially in time-based projects.

H1: Ceteris paribus, employers prefer workers from their home countries in online employment (time-based projects) relative to the sale contracts of outsourcing service (fixed-price projects).

\subsection{The Impact of Information Change on Home Bias}

With the implementation of the monitoring system, employers can reduce their uncertainty by monitoring, rely less on the trust-based relational contracting [48], and reduce their home bias. First, the monitoring system helps to alleviate hidden action issues and decrease workers' probability to shirk. When the monitoring system could automatically take screenshots and keep the log files of the project progress for employers to check anytime, both the shirking probability of foreign workers and that of domestic workers are reduced to a similarly low level. As such, the monitoring system serves as a prime example of process control mechanism and substitutes for relational contracting [49]. 
Moreover, owing to the precise monitoring records, employers could provide more timely and specific instructions for workers to help them perform more efficiently. Specifically, regardless of workers' home countries and their trustworthiness, employers could keep their cost uncertainty low and ensure their own profit from the projects. In other words, when employers try to lower their cost uncertainty in a platform with the monitoring system already available, they could more tend to rely on monitoring instead of signal exaction from both the group-specific and the individual-specific signals [50]. In other words, the implementation of the monitoring system serves as an exogenous information change by lowing the ex post information asymmetry and reducing the shirking risk, which is expected to decrease statistical discrimination (if there is any). Therefore, we propose the following hypothesis:

H2: The implementation of the monitoring system can mitigate employers' preference towards workers from their home countries in online employment (timebased projects) relative to the sale contracts of outsourcing service (fixed-price projects).

\section{Research methodology}

\subsection{Data}

We obtained a dataset from www.freelancer.com (Freelancer), one of the largest online labor market platforms. On this platform, the employer can post a project, including its description, the budget and required skills, among others. In particular, the employer may specify the project as a fixed-price project by outsourcing it at a flat price (Figure 1-a), or a time-based project (an employment contract) by paying hourly wages to the hired worker (Figure 1-b). Workers could browse all the active or ongoing projects on the website and selectively bid for some of them. Due to the limit on the number of bids one can submit each month ${ }^{2}$, workers may select projects that maximize their expected total rewards on the projects they are likely to win. Finally, a contract is reached if the employer assigns the project to one or more workers ${ }^{3}$ and the contractor accepts the offer.

To rule out the effect of the auction format on employers' choices, we limit our analysis to projects using the most common public auction form ${ }^{4}$. Further, to construct a homogenous project sample, we focus on the most popular project category, i.e., "IT, software \& website". The descriptive statistics of our final dataset are shown in Tables 1 and 2. The dataset includes the

\footnotetext{
${ }^{2}$ Free members could submit 8 bids per month. Golden members could submit more. However, the percentage of golden members in our dataset is less than $0.1 \%$.

${ }^{3}$ All these projects with more than one winners are dropped from our sample.
}

following attributes: 1) user-level characteristics (e.g., the number of reviews, the nationality, and the tenure of a user measured in months); project-level characteristics (the description, the budget, the type of contract, the number of bidders and the average bid price, who was awarded and so on).

Table 1. Definitions Workers' Characteristics

\begin{tabular}{|l|l|}
\hline \multicolumn{1}{|c|}{ Variable } & \multicolumn{1}{c|}{ Variable definition } \\
\hline Bid Price & The bid price posted by the worker \\
\hline Milestone percentage & $\begin{array}{l}\text { A feature provided by Freelancer, it denotes } \\
\text { the percentage of controlled payments paid } \\
\text { to the worker during the project }\end{array}$ \\
\hline Bidder tenure month & $\begin{array}{l}\text { the worker's tenure at Freelancer measured } \\
\text { in months }\end{array}$ \\
\hline Homecountry & $\begin{array}{l}\text { A dummy variable }(0,1),=1 \text { if the worker } \\
\text { and the employer live in the same country }\end{array}$ \\
\hline Bid order rank & The sequence order of the worker's bid \\
\hline Preferred freelancer & $\begin{array}{l}\text { A dummy variable }(0,1),=1 \text { if the worker } \\
\text { won the "Preferred Freelancer Badge" }\end{array}$ \\
\hline Bidder developed & $\begin{array}{l}\text { A dummy variable }(0,1),=1 \text { if the worker } \\
\text { comes from a developed country }\end{array}$ \\
\hline Count rating & $\begin{array}{l}\text { The number of reviews entered by previous } \\
\text { employers }\end{array}$ \\
\hline
\end{tabular}

Table 2. Definitions of Project Characteristics

\begin{tabular}{|l|l|}
\hline Variable & Variable definition \\
\hline Time_based & $\begin{array}{l}\text { A dummy variable }(0,1),=1 \text { if the project is a } \\
\text { time-based project; =0 if it is a fixed-price } \\
\text { project }\end{array}$ \\
\hline $\begin{array}{l}\text { Log (employer } \\
\text { overall rating) }\end{array}$ & $\begin{array}{l}\text { The average overall contractor-entered ratings } \\
\text { for the employer (log-transformed) }\end{array}$ \\
\hline Language Eng & $\begin{array}{l}\text { A dummy variable }(0,1),=1 \text { if the project is } \\
\text { described in English }\end{array}$ \\
\hline Log (paid amount) & $\begin{array}{l}\text { Amount of dollars paid by the employer after the } \\
\text { project was completed (log-transformed) }\end{array}$ \\
\hline Log (budget max) & $\begin{array}{l}\text { The maximum of bid prices for this project set by } \\
\text { the employer (log-transformed) }\end{array}$ \\
\hline Log (title length) & $\begin{array}{l}\text { Number of characters in the project title (log- } \\
\text { transformed) }\end{array}$ \\
\hline $\begin{array}{l}\text { Log (description } \\
\text { length) }\end{array}$ & $\begin{array}{l}\text { Number of characters in the project description } \\
\text { posted by the employer (log-transformed) }\end{array}$ \\
\hline Employer developed & $\begin{array}{l}\text { A dummy variable }(0,1),=1 \text { if the employer } \\
\text { comes from a developed country }\end{array}$ \\
\hline
\end{tabular}

\subsection{Identification: a quasi-natural experiment} On February $5^{\text {th }}, 2014$, Freelancer rolled out its monitoring system for the first time, which enables employers to conveniently monitor the progress of timebased projects. Such a monitoring system automatically takes screenshots and keeps track of workers' effort input. As a result, workers couldn't shirk or intentionally finish the time-based projects in a low demanding way. Specifically, since the monitoring system is mandatory for all time-based projects and is not available for fixed-price projects, we use the fixedprice projects as the control group and the time-based projects as the treatment group.

\footnotetext{
${ }^{4}$ In such a case, projects like special contracts with NDA, featured projects, sealed projects, fulltime jobs, those using the non-dollar currency, those written in non-English are dropped from our sample.
} 


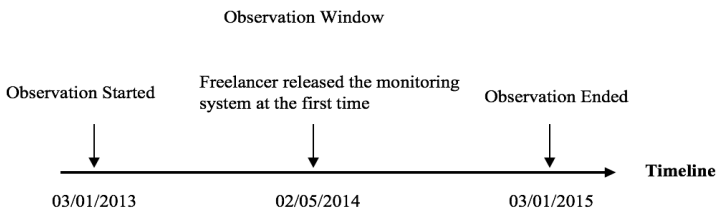

Figure 1. A Timeline of the Observation Window

According to the previous literature on statistical discrimination [15] and taste-based discrimination [16], two distinct predictions can be made based on different assumptions about the underlying mechanisms of home bias. For one thing, since statistical discrimination is contingent on the availability of individual-specific information, monitoring might lower the need for information extraction based on group-specific signals and hence lower the extent of statistical home bias. For another, given that taste-based discrimination is merely based on preference, which is irrelevant to the availability of information and the expected productivity. Therefore, the implementation of the monitoring system might affect statistical discrimination but not taste-based discrimination. If statistic discrimination is at work, we may observe a significant decrease in the level of home bias. Therefore, we proposed the following predictions:

Table 3. Types of Discrimination and Predictions

\begin{tabular}{|l|l|}
\hline \multicolumn{1}{|c|}{$\begin{array}{c}\text { Forms of } \\
\text { Discrimination } \\
\text { Statistical } \\
\text { discrimination }\end{array}$} & \multicolumn{1}{c|}{$\begin{array}{c}\text { Dynamic Predictions about the } \\
\text { Change in Home Bias }\end{array}$} \\
\hline $\begin{array}{l}\text { Taste-based } \\
\text { discrimination }\end{array}$ & $\begin{array}{l}\text { system, employers' home bias decreases in } \\
\text { the treatment group, as compared to the } \\
\text { control group }\end{array}$ \\
$\begin{array}{l}\text { After the implementation of the monitoring } \\
\text { system, employers' home bias remains } \\
\text { unchanged in the treatment group, as } \\
\text { compared to the control group }\end{array}$ \\
\hline
\end{tabular}

\section{Measures and models}

\subsection{Propensity Score Matching}

To generate a more comparable sample, we deploy the propensity score matching method to match fixed-price projects with time-based projects [51-54]. Specifically, we identify project characteristics and employer characteristics which might be associated with the contract type $[38,53,55,56]$. Then, we match fixedprice projects with time-based projects according to the estimated propensity score. Further, we conduct a balance check of all the observed covariates [54] and find that the mean values of these covariates are not significantly different between the two groups. Our final sample includes 5,223 fixed-price projects and 5,223 time-based projects.

\footnotetext{
${ }^{5}$ Since we employ one-to-one matching without replacement, all the means of month dummies are equal. Because of the limitation of length, the complete list of the t-test of month dummies is suppressed for brevity.
}

Table 4. Balance Check for PSM

\begin{tabular}{|l|l|r|r|}
\hline \multirow{2}{*}{ Covariates } & Variables & \multicolumn{2}{|c|}{ Mean } \\
\cline { 2 - 4 } & & Treated & Control \\
\hline $\begin{array}{l}\text { Project } \\
\text { description [53] }\end{array}$ & Description length & 16.33 & 16.40 \\
\cline { 2 - 4 } & Title length & 5.77 & 5.81 \\
\hline Project size [53] & Paid amount & 250.25 & 286.15 \\
\hline $\begin{array}{l}\text { Environment } \\
\text { change [38] }\end{array}$ & Month dummies & 0.04 & 0.04 \\
\hline $\begin{array}{l}\text { Client's } \\
\text { knowledge [53] }\end{array}$ & Employer tenure month & 729.31 & 728.75 \\
\cline { 2 - 4 } & Employer overall rating & 4.89 & 4.90 \\
\hline
\end{tabular}

\begin{tabular}{|l|c|r|r|c|}
\hline \multirow{2}{*}{ Covariates } & \multirow{2}{*}{$\%$ tobias } & \multicolumn{2}{|c|}{ t-test } & \multirow{2}{*}{$\begin{array}{l}\text { V(T)/ } \\
\text { V(C) }\end{array}$} \\
\cline { 3 - 4 } & & $\mathbf{t}$ & p>t & \\
\hline \multirow{2}{*}{ Project description [53] } & -1.70 & -0.87 & 0.38 & $1.19^{*}$ \\
\cline { 2 - 4 } & -1.20 & -0.63 & 0.53 & $1.09^{*}$ \\
\hline Project size [53] & -1.00 & -1.42 & 0.16 & 1.04 \\
\hline $\begin{array}{l}\text { Environment change } \\
\text { [38] }\end{array}$ & 0.00 & 0.00 & 1.00 & $\cdot$ \\
\hline \multirow{2}{*}{ Client's knowledge [53] } & 0.10 & 0.03 & 0.97 & $0.94^{*}$ \\
\cline { 2 - 4 } & -1.00 & -0.46 & 0.65 & $0.83^{*}$ \\
\hline
\end{tabular}

\section{Measures and Models}

\subsection{Employers' Decision}

We estimate the coefficients of the dummy variable Homecountry $_{i j}$ on the decision of employers before and after the implementation of the monitoring system based on a linear probability model (LPM) with projectlevel fixed-effects and a conditional logit model. Taking the Logit model as an example, the probability of the employer of project $\mathrm{i}$ assigns a project to bidder $\mathrm{j}$ is $\operatorname{Pr}\left(\right.$ Project $_{i_{-}}$award_bidder $\left.{ }_{j}\right)$ and the utility that the employer of project $i$ obtains from hiring bidder $j$ is constructed as follows:

$\mathrm{U}\left(\right.$ Project $_{i_{-}}$award_bidder $\left.{ }_{j}\right)=\alpha_{i}+\beta_{1}$ Homecountry $_{i j}+$ $\beta_{2}$ Homecountry $_{i j} \times$ Time_based $_{i}+\beta_{3}$ After $_{i} \times$

Home country $_{i j}+\beta_{4}$ After ${ }_{i} \times$ Homecountry $_{i j} \times$

Time_based $_{i}+$ controls $\left(\right.$ Bidder $\left._{j}\right)+\varepsilon_{i j}$

where $\alpha_{i}$ means the project-level fixed effect. Specifically, the employer-level fixed effects are nested within the project-level fixed effects. Homecountry ${ }_{i j}$ denotes whether the employer of project $\mathrm{i}$ and bidder $\mathrm{j}$ are from the same country. controls $\left(\right.$ Bidder $_{j}$ ) include various bidders' related characteristics ${ }^{6} . \varepsilon_{i j}$ is assumed to follow the type-I extreme value distribution [57]. A significantly positive effect of Homecountry $i j$ prior to the implementation of monitoring systems (captured by $\hat{\beta}_{1}+\hat{\beta}_{2}$ ) suggests that employers hold home bias. Moreover, based on our previous discussions, if $\hat{\beta}_{4}$ is significantly negative, we could conclude that employers adjust their home bias according to the

\footnotetext{
${ }^{6}$ Within data, a contractor's average rating is almost constant during our observational period. Therefore, we didn't treat the contractor rating as a time-variant variable here.
} 
information change and there exists statistical discrimination [33].

\subsection{Empirical Result}

Based on the results of LPM and the Logit model, both the coefficients of Homecountry ${ }_{i j}\left(\hat{\beta}_{1}\right)$ and Homecountry $_{i j} \times$ Time_based $_{i}\left(\hat{\beta}_{2}\right)$ are significantly positive, which indicates that employers are more willing to hire workers from their home countries, especially for time-based contracts. Hence, Hypothesis 1 is supported. Moreover, the coefficient of After $_{i} \times$ Homecountry ${ }_{i j}\left(\hat{\beta}_{3}\right)$ is not significant, which suggests that we don't have a weak control problem. As expected, the coefficient of the After $\times$ Homecountry ${ }_{i j} \times$ Time_based $_{i}\left(\hat{\beta}_{4}\right)$ is significantly negative, which suggests that, for time-based projects, employers' additional preference for bidders from their home countries decreases as more ex post individual-specific information is accessible through the monitoring system. This lends support to Hypothesis 2 .

To better understand the strength and the economic value of home bias, next we examine the sizes of related coefficients. Specifically, we focus on the coefficients in the Logit model due to the nature of the decision process. Before the implementation of the monitoring system, the total effect of Homecountry $i j$ is 0.801 ( $\left.\hat{\beta}_{1}+\hat{\beta}_{2}=0.323+0.478=0.801\right)$ while the coefficient of $\log$ (bid price) is -1.592 . In this sense, employers are willing to pay $65.4 \%(\exp (0.801 / 1.592)$ $1=1.654-1=0.654)$ more to domestic workers than to foreign workers, all else equal. Given that the average hourly wage of winners in time-based projects is 26.23 dollars, the effect of home bias translates to a premium of 17.15 dollars for domestic workers. However, after the deployment of the monitoring system, the effect of Homecountry $i j$ reduces to 0.419 , implying that domestic workers can still charge $30.1 \%^{7}$ more as compared to foreign workers, all else equal. In other words, the economic value of Homecountry $i j$ decreases to 7.90 dollars $^{8}$. Since only the level of statistical discrimination may decrease due to the availability of ex post individual-specific information, our finding demonstrates that roughly $54.0 \%{ }^{9}$ of home bias is driven by statistical discrimination. Given that monitoring is very likely to be imperfect and it could not help to alleviate the ex ante information asymmetry, employers may still, to some extent, perform statistical discrimination after the implementation of the monitoring system. Therefore, our estimate of the percentage of home bias driven by statistical

\footnotetext{
${ }^{7} \exp (0.419 / 1.592)-1=1.301-1=0.301$

${ }^{8} 26.23 * 30.1 \%=7.90$
}

discrimination is probably relatively conservative. To sum up, both Hypotheses 1 and 2 are supported.

Table 5. Estimation Results of LPM and Logit

\begin{tabular}{|c|c|c|c|c|}
\hline \multirow{2}{*}{\begin{tabular}{|l|} 
Sample \\
Model \\
\end{tabular}} & \multicolumn{2}{|c|}{ Full sample } & \multicolumn{2}{|c|}{ Matched sample } \\
\hline & LPM & Logit & LPM & Logit \\
\hline \multirow[t]{2}{*}{ Homecountry } & $0.023^{* * *}$ & $0.368 * * *$ & $0.022 * * *$ & $0.323 * * *$ \\
\hline & $(0.005)$ & $(0.064)$ & $(0.008)$ & $(0.107)$ \\
\hline \multirow[t]{2}{*}{$\begin{array}{l}\text { Time_based } \times \\
\text { Homecountry } \\
\end{array}$} & $0.061 * * *$ & $0.458^{* * *}$ & $0.061 * * *$ & $0.478^{* * *}$ \\
\hline & $(0.016)$ & $(0.152)$ & $(0.018)$ & $(0.175)$ \\
\hline \multirow[t]{2}{*}{ After $\times$ Homecountry } & 0.008 & 0.102 & 0.009 & 0.127 \\
\hline & $(0.006)$ & $(0.076)$ & $(0.010)$ & $(0.131)$ \\
\hline \multirow[t]{2}{*}{$\begin{array}{l}\text { Time_based } \times \text { After } \\
\times \text { Xomecountry }\end{array}$} & $-0.052 * * *$ & $-0.443 * *$ & $-0.047 * *$ & $-0.382 *$ \\
\hline & $(0.019)$ & $(0.192)$ & $(0.021)$ & $(0.221)$ \\
\hline \multirow[t]{2}{*}{ Log bid price } & $-0.082 * * *$ & $-1.707 * * *$ & $-0.080^{* * *}$ & $-1.592 * * *$ \\
\hline & $(0.001)$ & $(0.016)$ & $(0.001)$ & $(0.025)$ \\
\hline \multirow[t]{2}{*}{ Bidder developed } & $0.029 * * *$ & $0.477 * * *$ & $0.029 * * *$ & $0.475^{* * *}$ \\
\hline & $(0.001)$ & $(0.022)$ & $(0.002)$ & $(0.036)$ \\
\hline \multirow[t]{2}{*}{$\begin{array}{l}\text { Log milestone } \\
\text { percentage }\end{array}$} & $-0.005^{* * *}$ & $-0.107 * * *$ & $-0.012 * * *$ & $-0.243 * * *$ \\
\hline & $(0.001)$ & $(0.014)$ & $(0.001)$ & $(0.020)$ \\
\hline \multirow[t]{2}{*}{\begin{tabular}{|l} 
Log count rating \\
\end{tabular}} & $0.016^{* * *}$ & $0.374 * * *$ & $0.018^{* * *}$ & $0.378 * * *$ \\
\hline & $(0.000)$ & $(0.006)$ & $(0.000)$ & $(0.009)$ \\
\hline \multirow[t]{2}{*}{ Log_bid_order_rank } & $-0.008 * * *$ & $-0.186 * * *$ & $-0.006^{* * *}$ & $-0.148 * * *$ \\
\hline & $(0.001)$ & $(0.010)$ & $(0.001)$ & $(0.016)$ \\
\hline \multirow[t]{2}{*}{ Preferred freelancer } & $0.007 * * *$ & $0.113 * * *$ & $0.007 * * *$ & $0.108^{* * *}$ \\
\hline & $(0.001)$ & $(0.016)$ & $(0.002)$ & $(0.026)$ \\
\hline Project fixed effects & yes & yes & yes & yes \\
\hline Observations & 530,229 & 530,229 & 199,604 & 199,604 \\
\hline R-squared & 0.041 & & 0.040 & \\
\hline 1 & 21026 & & & 12,378 \\
\hline
\end{tabular}

Notes: a) Our sample is only limited to projects with only one winner. b) Log (bidder tenure month) is not included in our model Robust standard errors clustered by projects are reported in parentheses; c) $* p<0.1,{ }^{* *} p<0.05,{ }^{* * *} p<0.01$.

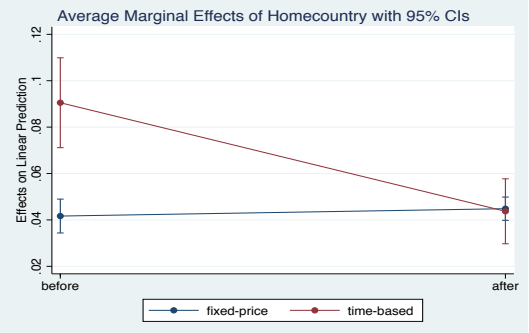

Figure 2. Marginal Effect of the "Homecountry" Dummy on Winning Probability

\subsection{Heterogeneous Treatment Effects in Different Sub-categories}

In our main analysis, we found that employers hold home bias and the bias becomes weaker after the implementation of the monitoring system. In line with this finding, we expect that the magnitude of such a change should be contingent on the observability of the project performance and the effectiveness of the monitoring system. As such, we should observe a more significant effect of the implementation of the monitoring system in projects whose outcomes are easier to be tracked by the monitoring system. For projects relying on creative thinking or background

${ }^{9}(0.654-0.301) / 0.654 * 100 \%=54.0 \%$ 
operations, the impact of monitoring might be very limited. Therefore, we explore the heterogeneous treatment effects in top 5 subcategories ranked by the number of projects. Among these five subcategories, two subcategories are expected to be easier to monitor (html and html5) based on our interviews with programmers. Overall, we find that the implementation of the monitoring system effectively reduces employers' home bias in these two subcategories (html and html5) but not in the other three ones. Therefore, the result supports the causal relationship between monitoring and the weakened home bias.

Table 6. Heterogeneous Treatment Effects

\begin{tabular}{|c|c|c|c|c|c|}
\hline Subcategory & HTML & Wordpress & MySQL & \begin{tabular}{|l|} 
jQuery / \\
Prototype \\
\end{tabular} & HTML5 \\
\hline Model & LPM & LPM & LPM & LPM & LPM \\
\hline \multirow[t]{2}{*}{ Homecountry } & $0.027 * * *$ & 0.012 & $0.029^{*}$ & 0.023 & -0.006 \\
\hline & $(0.005)$ & $(0.014)$ & $(0.016)$ & $(0.023)$ & $(0.018)$ \\
\hline \multirow[t]{2}{*}{$\begin{array}{l}\text { Time_based } \times \\
\text { Homecountry }\end{array}$} & $0.048^{* *}$ & 0.001 & 0.092 & 0.040 & $0.177^{* * *}$ \\
\hline & $(0.019)$ & $(0.040)$ & $(0.066)$ & $(0.064)$ & $(0.060)$ \\
\hline \multirow[t]{2}{*}{$\begin{array}{l}\text { After } \times \text { Homeco } \\
\text { untry }\end{array}$} & 0.008 & 0.008 & 0.008 & 0.008 & $0.053^{* *}$ \\
\hline & $(0.006)$ & $(0.017)$ & $(0.021)$ & $(0.028)$ & $(0.022)$ \\
\hline \multirow[t]{2}{*}{$\begin{array}{l}\text { Time_based } \\
\times \text { After } \\
\times \text { Homecountry }\end{array}$} & $-0.040 *$ & -0.032 & -0.018 & -0.018 & $-0.193 * *$ \\
\hline & $(0.023)$ & $(0.056)$ & 9) & $(0.087)$ & $(0.076)$ \\
\hline \multirow[t]{2}{*}{$\begin{array}{l}\begin{array}{l}\text { Bidder } \\
\text { developed }\end{array} \\
\end{array}$} & $0.021 * * *$ & $0.028 * * *$ & $0.020 * * *$ & $0.029 * * *$ & $0.039^{* * *}$ \\
\hline & $(0.002$ & $(0.00$ & $(0.005)$ & $(0.007)$ & $(0.008)$ \\
\hline \multirow[t]{2}{*}{ Log (bid price) } & $-0.060 * * *$ & $-0.072 * * *$ & $-0.085^{* * *}$ & $-0.086^{* * *}$ & $-0.061 * * *$ \\
\hline & $(0.001)$ & $(0.002)$ & $(0.003)$ & $(0.004)$ & $(0.004)$ \\
\hline \multirow[t]{2}{*}{$\begin{array}{l}\text { Log (milestone } \\
\text { percentage) }\end{array}$} & $-0.002 * *$ & $-0.006^{* * *}$ & $-0.006^{* *}$ & 0.004 & $-0.007 * *$ \\
\hline & $(0.001)$ & $(0.002)$ & $(0.002)$ & $(0.003)$ & $(0.003)$ \\
\hline \multirow[t]{2}{*}{$\begin{array}{l}\text { Log (count } \\
\text { rating) }\end{array}$} & $0.013^{* * *}$ & $0.011^{* * *}$ & $0.023^{* * *}$ & $0.018 * * *$ & $0.012 * * *$ \\
\hline & $(0.000)$ & $(0.001)$ & $(0.001)$ & $(0.001)$ & $(0.001)$ \\
\hline \multirow[t]{2}{*}{$\begin{array}{l}\text { Log (bid order } \\
\text { rank) }\end{array}$} & $-0.002 * * *$ & $-0.017 * * *$ & $-0.005^{* *}$ & $-0.011^{* * *}$ & $-0.010^{* * *}$ \\
\hline & $(0.001)$ & $(0.002)$ & $(0.002)$ & $(0.003)$ & $(0.003)$ \\
\hline \multirow[t]{2}{*}{$\begin{array}{l}\text { Preferred } \\
\text { freelancer }\end{array}$} & $0.009^{* * *}$ & $0.015 * * *$ & -0.002 & 0.008 & $0.019 * * *$ \\
\hline & $(0.001)$ & $(0.003)$ & $(0.004)$ & $(0.005)$ & $(0.005)$ \\
\hline $\begin{array}{l}\text { Project fixed } \\
\text { effects }\end{array}$ & yes & yes & yes & yes & yes \\
\hline Observations & 339,899 & 46,986 & 39,271 & 22,890 & 21,696 \\
\hline R-squared & 0.032 & 0.038 & 0.048 & 0.040 & 0.032 \\
\hline $\begin{array}{l}\text { Number of } \\
\text { projects }\end{array}$ & 15,503 & 2,482 & 2,904 & 1,728 & 1,239 \\
\hline
\end{tabular}

\section{Robustness Check}

\subsection{Alternative Models}

In the main analysis, we employ both the LPM and Logit models to explore employers' hiring decisions by balancing multiple workers' characteristics and bid prices, etc. To verify the robustness of our results, we follow the model in the previous discrimination literature by including the worker-specific fixed-effects [8] and tracking the change in the effect of the Homecountry $y_{i j}$ dummy. Specifically, based on the covariates listed in the Propensity Score Matching section (except for the month dummies), we match time- based projects posted prior to the implementation of the monitoring system with those time-based projects posted after its implementation. We compare the impact of Homecountry ${ }_{i j}$ dummy on the probability of bidder $\mathrm{j}$ being hired by the employer of project $\mathrm{i}\left(\operatorname{Pr}\left(\right.\right.$ Hire $\left.\left._{i j t}\right)\right)$ before and after within the full sample and the matched sample.

$$
\begin{aligned}
\operatorname{Pr}\left(\text { Hire }_{i j t}\right)=\alpha_{j}+ & \beta_{1} \text { Homecountry }_{i j}+\beta_{2} \text { After }_{i} \\
& +\beta_{3} \text { After }_{i} \times \text { Homecountry }_{i j} \\
& \left.+ \text { controls }_{\left(\text {bidder }_{j}\right.}\right)+\gamma_{t}+\varepsilon_{j t}
\end{aligned}
$$

where $\alpha_{j}$ denotes bidder-specific fixed-effects. The notations of all the other covariates are similar to those in the main result. Additionally, we also control for the time fixed-effects and cluster the standard errors by workers instead of projects. Further, following Åslund et al. [8], we estimate the change in workers' probability of being hired in the Linear Probability Model. As Table 6 shows, after the monitoring system implementation, the positive effect of the Homecountry Hij $_{j}$ dummy on the probability of being hired significantly decreases, which is highly consistent with our main result.

\subsection{Placebo Tests}

To reinforce the credibility of our main finding, we conduct two additional placebo tests. First, we assign a placebo intervention to the middle of our pre-treatment period (August $1^{\text {st }}, 2013$ ) and check whether there exists a pre-treatment decrease tendency in home bias prior to the actual implementation of monitoring systems. We find that the interaction between the "pseudo" After dummy and the Time_based dummy is insignificant. Second, following Abadie et al. [58], we randomly reassign the treatment to the projects and run the same model with the placebo treatment assignment. We replicate the analysis for 100 times $^{10}$ and generate the distribution of placebo treatment effects based on the "pseudo" treatments of monitoring intervention. By comparing the estimated coefficient of three key covariates to the whole distribution of "placebo" treatment effects, we find that it is unlikely to observe a similar size of treatment effect by chance, which lends support to the causal relationship between monitoring and the drop in home bias.

\subsection{Other Analyses}

To further check the robustness of our conclusions, we conduct additional analyses which are suppressed because of the limitation of length. First, we rerun the model with a shorter range of observational window (night months before and after; six months before and after) and still find a consistent result. Second, we conduct a falsification test based on employers' project

\footnotetext{
${ }^{10}$ To save the computation time, we employ the LPM to estimate the placebo treatment effects.
} 
experience. We expect that employers who have never posted a time-based project should not be affected by the implementation of the monitoring system. Hence, we rerun the model with employers with no time-based project experience and find their home bias doesn't decrease. Third, to ensure the workers are comparable and similar between the treatment group and the control group, we limit our sample to the bids which are submitted by those workers who bid for both fixed-price and time-based projects. The result of the restricted sample is still highly consistent with our main findings.

\section{Discussion}

\subsection{Key Findings and Implications}

Based on a quasi-natural experiment wherein the platform introduces a monitoring system for time-based projects, we explore the existence of employers' preference for workers from their home countries and the change in their preference after the implementation of the monitoring system. First, our estimation results suggest that there exists a home bias towards workers in online employment. Second, the monitoring system implementation reduces the ex post information asymmetry regarding hidden actions and lowers employers' home bias. Based on the different predictions from taste-based discrimination and statistical discrimination assumptions, we suggest that employers' home bias is more likely to be driven by statistical discrimination.

We add to the previous literature in three ways. First, this is the first study that confirms the existence of home bias in online employment. Despite the rich literature on home bias in equity and trade, the existence of home bias in online employment remains an open question. Åslund et al.'s [8] study might be the most relevant paper to ours. They found that immigrant managers show less discrimination against immigrant applicants in Sweden. However, given that their limited data from only one country, they could not disentangle the impact of the similar immigrant identity on hiring decisions from that of home bias. Moreover, they also failed to control for the informational difference between immigrant managers and native managers. Second, we also contribute to the emerging stream of research on the discrimination studies based on dynamic predictions and quasi-experiments [33, 34]. By now, the most popular method applied in discrimination studies is audit test [32]. However, as listed by Heckman and Siegelman [59] and Heckman [31], the audit studies suffer from the fact that the differences between the auditors in a pair are not well controlled or perfectly manipulated, and the non-double-blind research setting [32]. As Rubineau and Kang [33] stated, "The key to identifying statistical discrimination lies in scrutinizing its dynamic rather than static predictions.” By checking the consistency between the predictions based on statistical discrimination assumption and the actual observed result, we could build a more robust causal relationship between the information change and the dynamic change in discrimination, and subsequently identify the mechanism of discrimination. Third, our paper also contributes to the recent research on the discrimination phenomenon in the "Gig" economy. It has been found that there exists racial discrimination in on-demand short-term accommodation service [22] and on-demand E-hailing service [21]. We contribute to this stream of discrimination literature by showing that the discrimination based on the similarity of the home country is also one prevalent discrimination in the "Gig" economy. Our study suggests that by improving some platform-level information policies, we could increase the fairness of the "Gig" economy without reducing the market efficiency. Specifically, "Gig" economy platforms could provide more IT-enabled tools to help to lower the information asymmetry and mitigate the discrimination issues. Meanwhile, high-quality workers from the minority group could self-signal themselves by providing more individual information or join those platforms with less information asymmetry.

\subsection{Concluding Remark}

Using a unique large-scale data set from one of the prevalent online labor platforms, we document the existence of home bias in the online employment setting for the first time. Moreover, owing to the quasi-natural experiment design, we conclude that the implementation of the monitoring system lowers employers' home bias by $54.0 \%$. Our result suggests that when information is limited, employers might employ statistical discrimination and prefer to hire workers from their home countries. This kind of discrimination could be alleviated without the loss of market efficiency if the platform makes some changes to its information policies and reduces the ex ante or ex post information asymmetry. Overall, our study provides support for the existence of statistical home bias in the context of online employment.

\section{References}

[1] Kugler, A.D. and G. Saint-Paul, Hiring and firing costs, adverse selection and long-term unemployment. 2000: IZA.

[2] Hendricks, W., L. DeBrock, and R. Koenker, Uncertainty, hiring, and subsequent performance: The NFL draft. Journal of Labor Economics, 2003. 21(4): p. 857-886.

[3] Fryer, R. and M.O. Jackson, A categorical model of cognition and biased decision-making. The BE Journal of Theoretical Economics, 2008. 8(1): p. 1935-1704.

[4] Bertrand, M., D. Chugh, and S. Mullainathan, Implicit discrimination. American Economic Review, 2005: p. 94-98.

[5] Hortaçsu, A., F. Martínez-Jerez, and J. Douglas, The geography of trade in online transactions: Evidence from eBay and mercadolibre. American Economic Journal: Microeconomics, 2009. 1(1): p. 53-74. [6] Coval, J.D. and T.J. Moskowitz, Home bias at home: Local equity preference in domestic portfolios. The Journal of Finance, 1999. 54(6): p. 2045-2073. 
[7] Lin, M. and S. Viswanathan, Home bias in online investments An empirical study of an online crowdfunding market. Management Science, 2015. 62(5): p. 1393-1414.

[8] Åslund, O., L. Hensvik, and O.N. Skans, Seeking similarity: How immigrants and natives manage in the labor market. Journal of Labor Economics, 2014. 32(3): p. 405-441.

[9] Richard, O.C., Racial diversity, business strategy, and firm performance: A resource-based view. Academy of management journal, 2000. 43(2): p. 164-177.

[10] Obstfeld, M. and K. Rogoff, The six major puzzles in international macroeconomics: is there a common cause? NBER macroeconomics annual, 2000. 15: p. 339-390.

[11] Cooper, I. and E. Kaplanis, Home bias in equity portfolios, inflation hedging, and international capital market equilibrium.

Review of Financial Studies, 1994. 7(1): p. 45-60.

[12] Helliwell, J.F., How much do national borders matter? 2000: Brookings Institution Press.

[13] Lewis, K.K., Trying to explain home bias in equities and consumption. Journal of economic literature, 1999. 37(2): p. 571-608. [14] Phelps, E.S., The statistical theory of racism and sexism. The american economic review, 1972. 62(4): p. 659-661.

[15] Arrow, K.J., The theory of discrimination. 1973.

[16] Becker, G.S., The economics of discrimination. 2010: University of Chicago press.

[17] French, K.R. and J.M. Poterba, Investor Diversification and International Equity Markets. American Economic Review, 1991. 81(2): p. 222-226.

[18] Brunetti, A., G. Kisunko, and B. Weder, Institutional obstacles to doing business: region-by-region results from a worldwide survey of the private sector. 1997

[19] Gefen, D. and E. Carmel, Is the world really flat? A look at offshoring at an online programming marketplace. MIS quarterly, 2008: p. 367-384.

[20] Ghani, E., W.R. Kerr, and C. Stanton, Diasporas and outsourcing: evidence from oDesk and India. Management Science, 2014. 60(7): p. 1677-1697.

[21] Ge, Y., et al., Racial and gender discrimination in transportation network companies, 2016, National Bureau of Economic Research.

[22] Edelman, B., M. Luca, and D. Svirsky, Racial discrimination in the sharing economy: Evidence from a field experiment. American Economic Journal: Applied Economics, 2017. 9(2): p. 1-22.

[23] Todisco,M.,Share and Share Alike: Considering Racial Discrimination in the Nascent Room-Sharing Economy. Stan. L. Rev. Online, 2014. 67: p. 121.

[24] Belzer, A. \& N. Leong, The New Public Accommodations. 2016. [25] Forman, C., A. Ghose, and A. Goldfarb, Competition between local and electronic markets: How the benefit of buying online depends on where you live. Management science, 2009. 55(1): p. 47-57.

[26] Forman, C., A. Goldfarb, and S. Greenstein, The Internet and local wages: A puzzle. The American Economic Review, 2012. 102(1): p. 556-575.

[27] Sorenson, O. and T.E. Stuart, Syndication networks and the spatial distribution of venture capital investments 1 . American journal of sociology, 2001. 106(6): p. 1546-1588.

[28] Burtch, G., A. Ghose, and S. Wattal, Cultural differences and geography as determinants of online prosocial lending. MIS Quarterly, 2014. 38(3): p. 773-794.

[29] Bergstrand, J.H., The gravity equation in international trade: some microeconomic foundations and empirical evidence. The review of economics and statistics, 1985: p. 474-481.

[30] Bertrand, M. and S. Mullainathan, Are Emily and Greg more employable than Lakisha and Jamal? A field experiment on labor market discrimination. AER, 2004. 94(4): p. 991-1013.

[31] Heckman, J.J., Detecting discrimination. The Journal of Economic Perspectives, 1998. 12(2): p. 101-116.

[32] Bertrand, M. and E. Duflo, Field experiments on discrimination. Handbook of Economic Field Experiments, 2017. 1: p. 309-393.
[33] Rubineau, B. and Y. Kang, Bias in white: A longitudinal natural experiment measuring changes in discrimination. Management Science, 2012. 58(4): p. 660-677.

[34] Goldin, C. and C. Rouse, Orchestrating impartiality: The impact of" blind" auditions on female musicians, 1997, NBER.

[35] Doleac, J.L. and B. Hansen, Does "ban the box" help or hurt low-skilled workers? Statistical discrimination and employment outcomes when criminal histories are hidden, 2016, NBER.

[36] Hong, Y. and P.A. Pavlou, On Buyer Selection of Service Providers in Online Outsourcing Platforms for IT Services. ISR, 2017. [37] Simon, H.A., A formal theory of the employment relationship. Econometrica: Journal of the Econometric Society, 1951: p. 293-305. [38] Banerjee, A.V. and E. Duflo, Reputation effects and the limits of contracting: A study of the Indian software industry. The Quarterly Journal of Economics, 2000. 115(3): p. 989-1017.

[39] Mani, D., A. Barua, and A.B. Whinston, An empirical analysis of the contractual and information structures of business process outsourcing relationships. Information Systems Research, 2012. 23(3-part-1): p. 618-634.

[40] Aigner, D.J. and G.G. Cain, Statistical theories of discrimination in labor markets. ILR Review, 1977. 30(2): p. 175-187.

[41] Schwab, S., Is statistical discrimination efficient? The American Economic Review, 1986. 76(1): p. 228-234.

[42] Zhao, R.R., All-or-nothing monitoring. The American Economic Review, 2008. 98(4): p. 1619-1628.

[43] Pierce, L., D.C. Snow, and A. McAfee, Cleaning house: The impact of information technology monitoring on employee theft and productivity. Management Science, 2015. 61(10): p. 2299-2319.

[44] Zucker, L.G.,Production of trust: Institutional sources of economic structure, 1840-1920. Research in organizational behavior, 1986.

[45] Gambetta, D.,Trust:Making and breaking cooperative relations. 1988.

[46] Gulati, R., Does familiarity breed trust? The implications of repeated ties for contractual choice in alliances. Academy of management journal, 1995. 38(1): p. 85-112.

[47] Zajonc, R.B., Attitudinal effects of mere exposure. Journal of personality and social psychology, 1968. 9(2p2): p. 1.

[48] Williamson, O.E., The economic intstitutions of capitalism. 1985: Simon and Schuster.

[49] Srivastava, S.C. and T.S. Teo, Contract performance in offshore systems development: Role of control mechanisms. Journal of Management Information Systems, 2012. 29(1): p. 115-158.

[50] Belman, D. and J.S. Heywood, Sheepskin effects in the returns to education: An examination of women and minorities. The Review of Economics and Statistics, 1991: p. 720-724.

[51] Xue, M., L.M. Hitt, and P.-y. Chen, Determinants and outcomes of internet banking adoption. Management Science,2011.57(2): p.291. [52] Hong, Y., C. Wang, and P.A. Pavlou, Comparing open and sealed bid auctions: evidence from online labor markets. Information Systems Research, 2015. 27(1): p. 49-69.

[53] Lin, M., Y. Liu, and S. Viswanathan, Effectiveness of reputation in contracting for customized production: Evidence from online labor markets. Management Science, 2016.

[54] Xu, K., et al., Battle of the channels: The impact of tablets on digital commerce. Management Science, 2016.

[55] Gopal, A. and K. Sivaramakrishnan, Research note-On vendor preferences for contract types in offshore software projects: The case of fixed price vs. time and materials contracts. Information Systems Research, 2008. 19(2): p. 202-220.

[56] Roels, G., U.S. Karmarkar, and S. Carr, Contracting for collaborative services. Management Science, 2010. 56(5): p. 849-863.

[57] Train, K.E., Discrete choice methods with simulation. 2009: Cambridge university press.

[58] Abadie, A., A. Diamond, and J. Hainmueller, Comparative politics and the synthetic control method. American Journal of Political Science, 2015. 59(2): p. 495-510.

[59] Heckman, J.J. and P. Siegelman, The Urban Institute audit studies: Their methods and findings. 1993. 